\title{
Endoscope-Assisted Cochlear Implantation
}

\author{
Enis Alpin Güneri · Yüksel Olgun \\ Department of Otorhinolaryngology, Dokuz Eylül University School of Medicine, Izmir, Turkey
}

Objectives. Our aim was to present our endoscope-assisted cochlear implantation (CI) technique, in which the middle ear landmarks were identified through the facial recess exposure by using an endoscopic view without elevating the tympanic annulus. The secondary goal was to assess whether the situation of difficult surgical exposure could be predicted by evaluating preoperative axial computed tomography (CT) examinations.

Methods. CT examinations and surgical outcomes of endoscope-assisted CI surgeries were analyzed.

Results. A total of 179 CI operations performed in 27 adults (15.1\%) and 152 children (84.9\%) were retrospectively evaluated. It was found that in 14 cases $(7.8 \%)$, endoscopic examination contributed substantially in identifying the round window (RW) membrane correctly. Endoscopic identification of the RW through the posterior tympanotomy enabled us to perform a straightforward surgery in all these cases, without the need for switching to a bony cochleostomy or alternative surgical techniques. The difficulty in the surgical exposure was predicted preoperatively by examining the axial CT scans in six of the 14 cases $(42.8 \%)$ for which endoscopic assistance was necessary in order to identify the RW correctly.

Conclusion. The main benefit of endoscope-assisted CI is the improved visibility leading to a panoramic view of the RW region. The implementation of transfacial recess endoscopic examination into the conventional CI technique is helpful to avoid problems during surgical orientation. However, the difficulty in the surgical exposure of the RW cannot be reliably predicted by the subjective evaluation of preoperative CT scans and more studies are needed to obtain reliable criteria.

Keywords. Cochlear Implants; Endoscope; Ear

\section{INTRODUCTION}

The standard technique for cochlear implantation (CI) is transmastoid posterior tympanotomy (PT; facial recess) approach that was described a half century ago [1]. It was recently argued that eliminating the mastoid air cell system may lead to undesired consequences like persistent negative middle ear pressure and tympanic membrane retractions [2-6] and the stimulation

\footnotetext{
- Received July 20, 2017

Revised October 12, 2017

Accepted October 27, 2017

- Corresponding author: Yuksel Olgun

Department of Otorhinolaryngology, Dokuz Eylül University School of Medicine, Kahramander Mahallesi, Özege Sitesi No. 8, Güzelbahçe, Izmir, Turkey

Tel: +90-506-702-1434, Fax: +90-232-278-9495

E-mail: yuksel.olgun@deu.edu.tr
}

of technological developments in the era of minimally invasive surgery resulted in description of alternative surgical techniques avoiding the mastoidectomy step in the procedure (Table 1) [720]. However, in some cases, it may simply become necessary to switch to an alternative method due to the limited anatomical vision of the round window (RW) region when looking through the PT opening. The temporal bone is a complex structure, with significant postnatal development and lateral growth; it was reported that an average of $12 \mathrm{~mm}$ of growth was seen directly between the sinodural angle and the RW between birth and adulthood [21,22]. Since an anteriorly and laterally located mastoid segment of the facial nerve (FN) is the main reason of a narrow PT window resulting in insufficient exposure of the RW region (Fig. 1), we hypothesized that some constitutional and developmental factors may lead to an unfavorable position of the RW creating a difficult surgical exposure through the PT.

Copyright $@ 2018$ by Korean Society of Otorhinolaryngology-Head and Neck Surgery.

This is an open-access article distributed under the terms of the Creative Commons Attribution Non-Commercial License (http://creativecommons.org/licenses/by-nc/4.0)

which permits unrestricted non-commercial use, distribution, and reproduction in any medium, provided the original work is properly cited. 

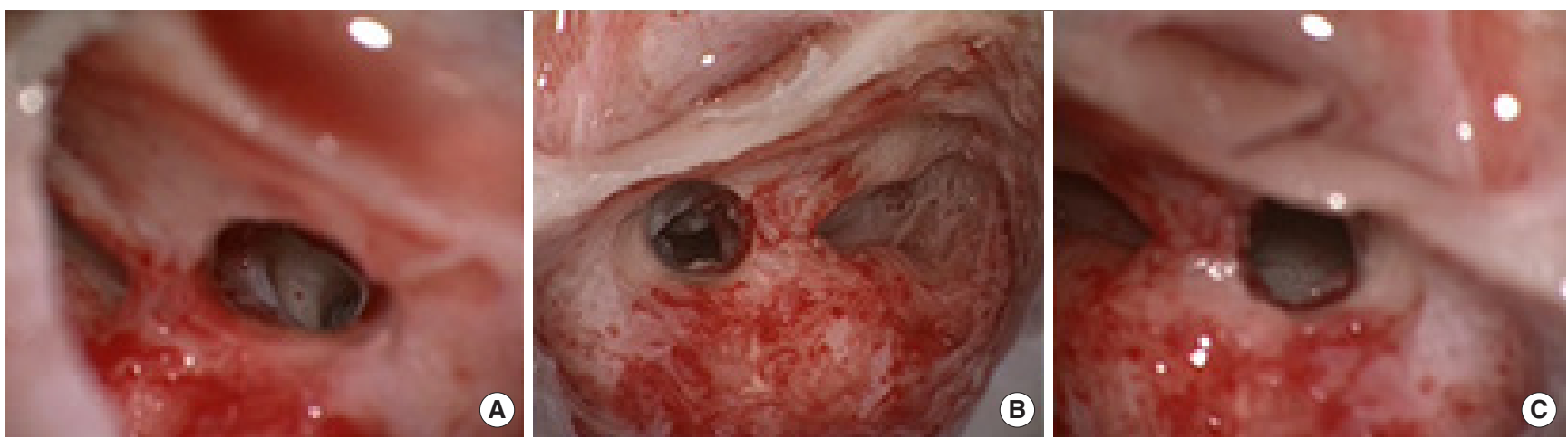

Fig. 1. Adequate microscopical exposure of the round window region through posterior tympanotomy (right ear). Stapedial tendon, posterior crus of the stapes, incudostapedial joint and round window region are clearly visualized (A). Inadequate microscopical exposure of the round window region through posterior tympanotomy (facial recess approach, right ear). Round window region can not be visualized through the window delineated by chorda tympani laterally, facial nerve medially and the short process of incus cranially. The incudostapedial joint, umbo can be noticed (B). The round window niche could not be fully exposed in spite of a maximally opened proper posterior tympanotomy window (Saint Thomas Hospital classification type llb) (C).

Table 1. Alternative $\mathrm{Cl}$ techniques

\begin{tabular}{lcl}
\hline Author & Year & \multicolumn{1}{c}{ Technique } \\
\hline Colletti et al. [7] & 1998 & Middle cranial fossa approach \\
Kronenberg et al. [8] & 2001 & Suprameatal approach \\
Kiratzidis et al. [9] & 2002 & Veria approach \\
Hausler [10] & 2002 & Pericanal electrode insertion \\
Huang et al. [11] & 2006 & Retrofacial approach \\
Sennaroglu and Aydin [12] & 2002 & Split ear canal \\
Warren et al. [13] & 2007 & Percutaneous Cl \\
Carfrae and Foyt [14] & 2009 & Canal wall down \\
Guneri [15] & 2016 & Endoscope-assisted Cl \\
Slavutsky and Nicenboim [16] & 2009 & Endomeatal approach \\
Lavinsky et al. [17] & 2010 & Combined approach \\
Kiumehr et al. [18] & 2013 & Transcanal approach \\
Marchioni et al. [19] & 2014 & Endoscopic Cl \\
Dia et al. [20] & 2014 & Transcanal endoscopic approach \\
\hline
\end{tabular}

$\mathrm{Cl}$, cochlear implantation.

This condition is well known by experienced surgeons, but had been rarely brought into consideration. A recent classification evaluating the accessibility of the RW membrane via the PT assorted those difficult cases as type III patients, in which the RW membrane cannot be identified even after drilling the RW niche (Table 2) [23]. Recent studies underlined the importance of preoperative high resolution computed tomography (CT) findings

\section{H I G H L I G H T S}

- Surgical landmarks can be more easily identified with the aid of endoscopes.

- Endoscopic evaluation can reduce risk of complications by minimizing surgical orientation.

- Axial computed tomography scans are useful to determine if the surgical exposure of the round window is difficult.
Table 2. STH classification and suggestions for cochleostomy choice (including the authors' suggestion for type III cases)

\begin{tabular}{|c|c|c|}
\hline Type & $\begin{array}{l}\text { RW visibility after } \\
\text { drilling the niche }\end{array}$ & Suggestion \\
\hline I & Complete & Membranous cochleostomy \\
\hline Ila & $50 \%-99 \%$ & Membranous \pm anteroinferior RW approach \\
\hline Ilb & $1 \%-49 \%$ & $\begin{array}{l}\text { Extended anteroinferior RW approach } \pm \text { bony } \\
\text { cochleostomy }\end{array}$ \\
\hline \multirow[t]{2}{*}{ III } & Impossible & Bony cochleostomy \\
\hline & & $\begin{array}{l}\text { Endoscopic identification of the RW membrane } \\
\text { through the facial recess and membranous } \\
\text { cochleostomy }\end{array}$ \\
\hline
\end{tabular}

STH, Saint Thomas Hospital; RW, round window.

and reported that the radiological evaluations correlated with the visibility of the RW $[24,25]$. Although the anatomical variations of the posterior tympanum and RW region were described in detail [26], problems in surgical orientation such as mistaking a wide subcochlear canaliculus with the RW niche may lead to inadvertent implantation attempts resulting in failure and other major complications may arise.

There are various options when it becomes necessary to change the surgical approach due to the insufficient microscopic vision (difficult surgical exposure) through the PT. One of them is the transcanal exposure by elevating a tympanomeatal flap, identification of the RW membrane, followed by insertion of the array delivered into the middle ear through the aditus or facial recess, sometimes splitting the posterior canal wall or laying the electrode in a groove created in the external auditory canal (EAC) [12,17-20]. Suprameatal approach and its modifications $[8,9]$, switching to an open cavity with reconstruction of the canal wall after implantation or blind sac closure of the EAC with fat obliteration of the cavity [14] are other techniques. Retrofacial [11] or middle fossa [7] approaches may rarely be used. However, we think that the simpler and better solution is to in- 

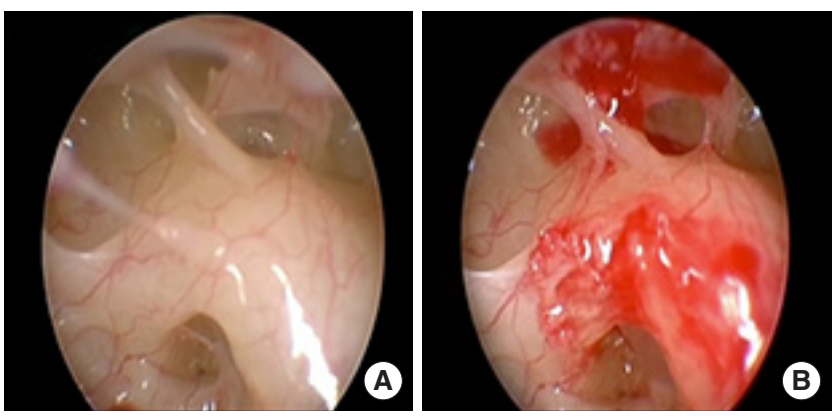

Fig. 2. Endoscopic view of the round window through the facial recess obtained with a $0^{\circ}, 4 \mathrm{~mm}$ rigid endoscope before $(A)$ and after (B) removing the round window niche (right ear).

sert an endoscope through the facial recess and obtain a panoramic view of the RW region. With significant advantages like the wide angle outlook and growth of the image as the tip of the endoscope comes closer, the small blood vessels on the roof (tegmen) of the RW niche can be clearly identified and the tegmen may be removed to obtain a full circumferential view of the RW membrane (Fig. 2).

Most studies advocate electrode insertion by performing a membranous cochleostomy through the RW membrane, not only to be more confident that the array is correctly placed in the scala tympani (ST) and minimizing the risk of injury to the residual hearing; but also to achieve a more optimal electrode position [27-29]. Bony cochleostomy, which may be used when there is limited access, is more undesirable; however, similar soft surgical techniques can be used and a proper electrode position may also be obtained with this technique as well [23]. For almost 10 years, we have used supplementary endoscopic examination of the middle ear landmarks through the PT without elevating the tympanic annulus, when it is difficult to achieve a complete exposure of the RW membrane by the microscopical view. In this article, we examined the records of such $\mathrm{CI}$ operations retrospectively and evaluated the utility and validity of this technique. We also evaluated whether the difficult surgical exposure could be predicted by examining preoperative axial computed high resolution CT scans.

\section{MATERIALS AND METHODS}

The data of $179 \mathrm{CI}$ operations, with endoscopic assistance when necessary, were retrospectively evaluated. There were 105 male $(58.6 \%)$ and 74 female $(41.3 \%)$ patients. The majority of the cases were children (152 cases, $84.9 \%$ ), but the age range was between 1 and 75 years (mean, 7.8 years). Of those 179 patients, $132(73.7 \%)$ were prelingually hearing impaired, the numbers of perilingual and postlingual patients were $15(8.3 \%)$ and $32(17.8 \%)$, respectively. Fourteen cases $(7.8 \%)$ had various inner ear abnormalities including enlarged vestibular aque-
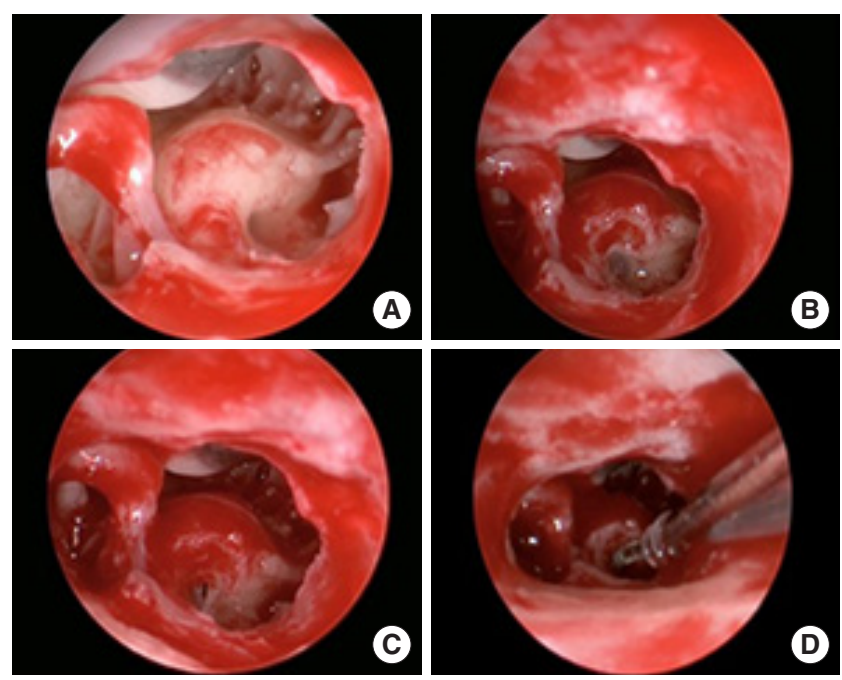

Fig. 3. Endoscopic view of the round window (RW) region obtained with a $0^{\circ}, 4 \mathrm{~mm}$ rigid endoscope inserted through the facial recess (right ear). RW region (A), RW membrane after removing the niche (B), membranous cochleostomy (C), electrode insertion (D).

duct (3.9\%), incomplete partition type II deformity $(2.2 \%)$, common cavity $(1.1 \%)$ and semicircular canal dysplasia $(0.5 \%)$.

A standard mastoidectomy and PT approach was used for all cases. Nucleus (Contour Advance; Cochlear, New South Wales, Australia), Advanced Bionics (HiFocus 1j, HiFocus Helix; Advanced Bionics, Valencia, CA, USA), Med-El (Classic Standard, Classic Compressed; Med-El, Innsbruck, Austria), and Oticon (Neuro Zti; Oticon Medical, Copenhagen, Denmark) implants were used according to various situations. Endoscope-assisted visualization of the RW region through the PT was performed in 14 cases $(7.8 \%)$ in which the RW membrane was not properly exposed under the microscopical view (Saint Thomas Hospital [STH] classification type IIb [23]). Rigid endoscopes with $0^{\circ}$ and $30^{\circ}$ (2.7 and $4 \mathrm{~mm}$ in width, 11 and $6 \mathrm{~cm}$ in length) and a HD (high-definition) camera system (Karl Storz, Tuttlingen, Germany) were used for the endoscopic evaluation. The RW region was visualized by inserting the endoscope through the PT without elevating the tympanic annulus (Fig. 3). After definitive identification of the RW and its membrane with the advantage of the panoramic view provided by the endoscopes, the inferior border of the RW niche was marked with the tip of a pick. Later, we switched to the microscope and drilled the RW niche (tegmen) using both hands until a circumferential view of the RW membrane is obtained. After proper exposure, the electrode was inserted through an opening in the RW membrane mostly under microscopical vision.

The position of the cochlea in the petrous bone, as well as the relationship between the FN and the RW was carefully evaluated on the preoperative axial CT scan in each patient preoperatively. First, we considered whether the region between the FN and the RW was deep enough, regarding that an adjacent posi- 
tion of these structures with a short distance and an insufficient depth between them might predict the inadequacy of a PT opening for a proper RW exposure (Fig. 4). Second, we hypothesized that an anteriorly inclined internal auditory canal (IAC) may predict an unfavorable position of the cochlea, which may also impede the surgical exposure of the RW through the PT. For that reason, we evaluated whether the IAC was roughly parallel to a horizontal line drawn on an axial CT cut connecting the posterior-lateral margins of both IACs or exhibit a significant anterior inclination (Fig. 5). An unfavorable situation was suspected to exist if both the space between the FN and the RW

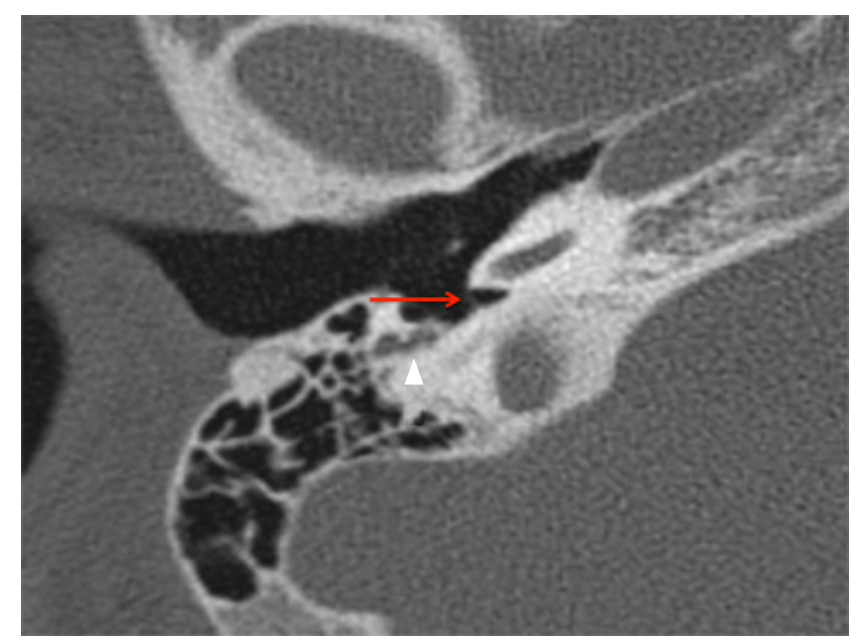

Fig. 4. The first parameter used to determine the adequacy of the exposure: the depth of the region between the mastoid segment of the facial nerve and the round window on an axial computed tomography scan was evaluated in order to assess whether the facial recess approach would provide an adequate exposure (right ear; arrow points to the round window, arrowhead points to the mastoid segment of the facial nerve). was shallow and there was an anterior inclination of the IAC. It was not intended to measure and calculate those two evaluation parameters due to their insufficient objectivity.

\section{RESULTS}

In 14 cases $(7.8 \%)$, endoscopic assistance was necessary to identify the RW membrane correctly during the operation. In all of them, less than half of the RW membrane was visible after drilling the niche (STH classification type IIb). The difficult exposures were experienced mostly in children, 10 of the 14 patients $(71.4 \%)$ in whom endoscopic assistance was necessary were children and difficult surgical exposure was predicted in five of these pediatric patients (50\%). Endoscopic identification of the RW through the PT enabled us to perform a regular surgery in all these 14 cases without the need for switching to a bony cochleostomy or other more invasive alternative techniques. Inadequate surgical exposure could be predicted preoperatively by identifying a shallow space between the FN and the $\mathrm{RW}$ in addition to a significant degree of unfavorable cochlear position in six of 14 cases $(42.8 \%)$. There were two pediatric cases with enlarged vestibular aqueduct anomaly in the difficult to expose group and no anomalies were detected in the remaining 12 patients. No operative difficulties in the microscopical surgical exposure were encountered and endoscopic assistance was not required for other 165 patients $(95.3 \%)$ in whom preoperative CT evaluations suggested that the depth of the RW was adequate and the IAC was not anteriorly inclined. In eight of the 14 endoscope-assisted cases, it was not able to predict the difficulty by examining the scans and endoscopic assistance was required in those eight out of the unpredicted 173 patients (4.6\%). Regarding the validity of preoperative CT examination
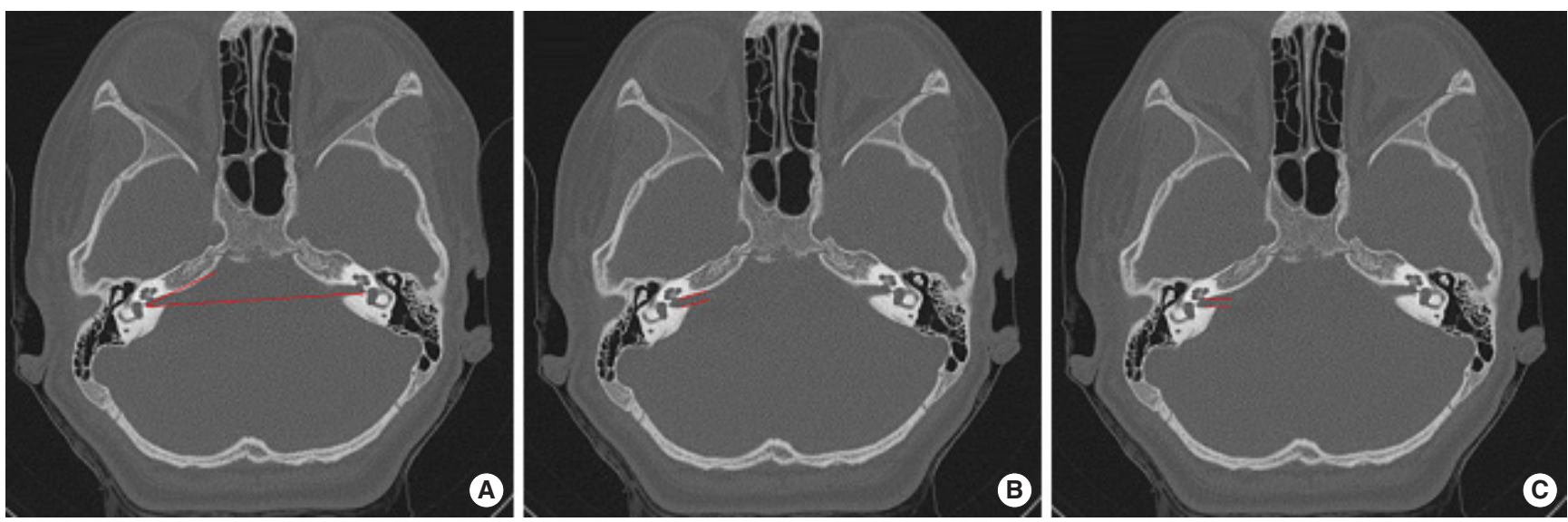

Fig. 5. The second parameter used to determine the adequacy of the exposure: the angle between the long axis of the IAC and a horizontal line drawn between the posterior borders of both internal auditory canals (IACs). (A) The angle is markedly increased on the right side and the IAC is inclined significantly anteriorly. (B) The IAC is nearly in horizontal orientation on the left side in comparison to (A). The expected orientation of the right IAC in relation to the location of the cochlea is illustrated in (C) (axial computed tomography scan). 
Table 3. The distribution of patients with difficult surgical exposure and those who were preoperatively predicted or not by evaluating the axial CT exam

\begin{tabular}{|c|c|c|}
\hline $\begin{array}{l}\text { Reliability of preoperative } \\
\text { CT evaluation }\end{array}$ & Total & $\begin{array}{l}\text { Difficult exposure group } \\
\text { (STH type llb) }\end{array}$ \\
\hline Number & 14 & 14 \\
\hline Pediatric case & 10 & $\begin{array}{l}2 \text { With enlarged vestibular } \\
\text { aqueduct, } 8 \text { with no anomaly }\end{array}$ \\
\hline Adult case & 4 & 4 With no anomaly \\
\hline True positive & 6 & 5 Pediatric, 1 adult \\
\hline False negative & 8 & 5 Pediatric, 3 adults \\
\hline Sensitivity (\%) & 42.8 & 30 \\
\hline Specificity (\%) & 100 & 100 \\
\hline Positive predictive value (\%) & 100 & 100 \\
\hline Negative predictive value (\%) & 95.3 & 94.4 \\
\hline
\end{tabular}

CT, computed tomography; STH, Saint Thomas Hospital.

in predicting the difficult surgical exposure, there were no false positive, 165 true negative, six true positive and eight false negative cases (Table 3).

\section{DISCUSSION}

The direct line of sight obtained by the microscope through the PT may not provide enough surgical exposure and sometimes it may be difficult to identify the RW and surrounding landmarks. A recent classification put forward the importance of this fact and reported that it was difficult to identify the RW membrane in up to $11 \%$ of adult and $22 \%$ of pediatric cases (STH classification types IIb) [23].

A careful examination of preoperative CT scans can enable the surgeon to anticipate and evaluate probable difficulties such as a high jugular bulbus, anteriorly located lateral sinus or a low hanging dura. It was reported that the intraoperative visibility of the RW membrane could be predicted radiologically by using some measurements to determine the distance and relationships between the FN and the RW, as well as the position of the cochlea along the axis of the PT window [24,25,28,30]. In light of these previous studies, we paid more attention in evaluating the distance between the FN and the RW on the axial CT scan to determine the adequacy of the width and depth of the posterior tympanum (Fig. 4). It was considered that a difficult exposure is likely if the FN and the RW were in an adjacent position with a short distance between them. We also thought that an unfavorable position of the cochlea within the petrous bone might occur as a result of constitutional factors or possibly due to the ongoing growth of the skull in children. It was thought that a more caudal, posterior and medial position of the cochlea and/or a more anterior and lateral position of the FN may cause difficulty for the exposure of the RW through a proper PT opening; so, we speculated that the angle between the IAC and a horizontal line demonstrating the coronal plane may be an additional radiologi- cal parameter in predicting the unfavorable position or orientation of the RW. Normally, the IAC is roughly parallel to the EAC and a horizontal line connecting the posterior-lateral borders of both IACs on an axial CT scan. We thought that, if the IAC is inclined anteriorly creating a considerable degree of angulation in relation to this horizontal line, it was likely that the cochlea may be located in a more caudal, posterior and medial position and a more difficult surgical exposure may be anticipated in such cases (Fig. 5). By using these two parameters, inadequate surgical exposure could be predicted on the preoperative axial CT scans in six of the 14 cases $(42.8 \%)$ up in our series. However, in eight of the 14 endoscope-assisted cases (57.2\%), it was not able to predict the difficulty by examining the scans.

It seems that the two radiological parameters evaluated in this study were not adequate for the evaluation of the difficulty in the exposure of the RW through the PT and showed that further studies were needed to obtain more reliable criteria. The weakness of our paradigm was the lack of quantitative evaluations of the depth of the posterior tympanum and cochlear position by using objective radiological measurements like segmentation techniques relative to the surrounding anatomical structures. However, further research is being conducted in order to evaluate our hypothesis with objective morphological and radiodiagnostical data. Also, the number of cases was not enough to draw a conceivable conclusion, but we think that quantitative evaluation of those two aforementioned features may be useful to anticipate the difficulty in the surgical exposure and a need for an alternative or assistive technique.

Previous studies suggested that the position of the electrode array in relation to the ST was strongly influenced by the insertion vector. RW (membranous) cochleostomy is considered more appropriate than promontory (bony) cochleostomy in this respect since the angle of insertion through the RW may provide the optimal vector for the desired position of the electrode [2729]. It is easier to identify the RW with a transcanal approach, but transcanal insertion vector may carry the risk of leading to a more lateral position of the array in the ST and may increase the battery energy needed to stimulate the spiral ganglion neurons. Also, elevating the tympanic annulus carries a significant risk of injury to the annulus or tympanic membrane $[20,31,32]$. We think that transfacial recess endoscopic identification of the RW obviates the need to switch to a transcanal approach. It is possible to determine the orientation of the basal turn endoscopically, providing information on spatial orientation (Fig. 6).

Endoscopic ear surgery (EES) has gained considerable popularity during the last decade $[26,29,31,33,34]$, and this enthusiasm encouraged the otologists to use endoscopes during conventional and alternative CI surgeries. The first advantage of EES is the endoscopic magnification, which is the growth of the visual field as the endoscope approaches near the object of interest. The second is the unique ability to visualize over the corners with the angled endoscopes. Both features contribute to 


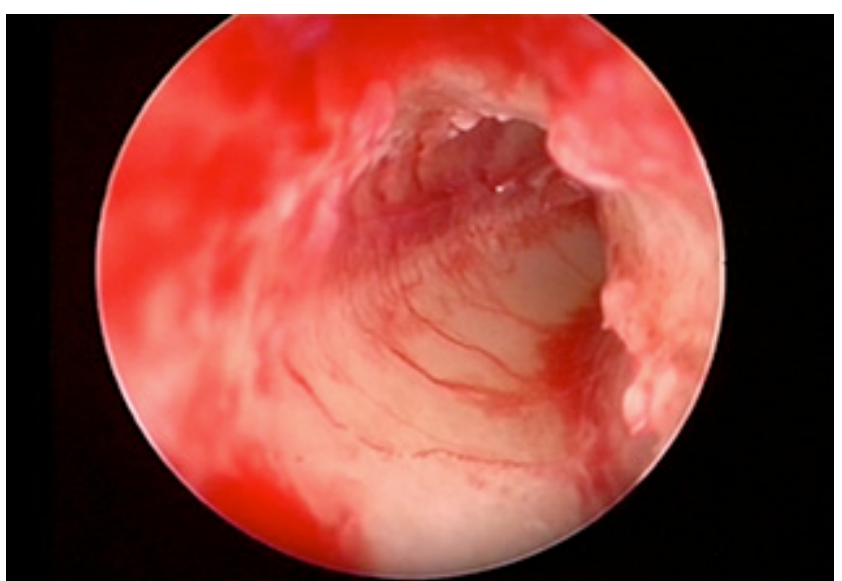

Fig. 6. Rigid endoscopic view $\left(0^{\circ}, 2.7 \mathrm{~mm}\right)$ of the scala tympani and modiolus (left ear).

Table 4. Classification of alternative cochlear implantation techniques

\begin{tabular}{ll}
\hline Transmeatal & Endoscope-assisted \\
\hline Endomeatal & Percutaneous \\
Suprameatal & Transcanal \\
& Transfacial recess \\
\hline
\end{tabular}

the benefit of obtaining a panoramic view of the anatomical structures, which may not be possible with the direct line of vision of the microscope. EES can be applied not only during the conventional approach, but also while using other alternative CI techniques (Table 1), which can be grouped as transmeatal (suprameatal and endomeatal) and endoscope-assisted (percutaneous, transcanal and transfacial recess) approaches (Table 4) $[15,19,20,31,34-37]$. The disadvantages of alternative techniques are electrode exposure or extrusion and cholesteatoma formation; ear canal or tympanic membrane injuries were reported to occur in almost half of the patients [20,32]. Endoscope-assisted approaches may necessitate individually customized drill guides in addition to the availability of image guided surgical technology $[35,36]$.

Our technique is an endoscope-assisted conventional PT approach; however, if there is limited visibility of the RW, $0^{\circ}$ and $30^{\circ}$ endoscopic examination through the facial recess is performed in addition. A panoramic view of the RW is obtained by doing so and the RW membrane can be circumferentially displayed in contrast to the usual microscopic view, which is in line with the angle of the microscope. Endoscopic examination enables the surgeon to determine the orientation of the RW membrane and the fustis, area concamerata and the subcochlear tunnel can also be clearly identified (Fig. 3). Then the surgeon can switch to the microscope, and after drilling the RW niche, may obtain a sufficient microscopical view in order to precede the following steps of the surgery or a membranous cochleostomy can be performed endoscopically. It is also possible to visualize inside the ST endoscopically through the cochleostomy in order to assess the orientation of the modiolus and other anatomical features (Fig. 6). Alhough we sometimes do in suitable situations, it is not recommended to insert the electrode under endoscopic view (Fig. 3). Since some electrodes are particularly flexible and springy, while some others may require removal of the stylet with one hand and insertion with the other, it is an unnecessary challenge to try to insert the electrode while one hand is holding the endoscope. Our technique is different from other recently published series $[19,37]$ in that the annulus is not elevated and endoscopy of the RW is performed through the PT opening. In our experience, it is not necessary to elevate the annulus and obtain a transcanal microscopic and/or endoscopic exposure and we think that transcanal exploration is prone to iatrogenic annulus and/or tympanic membrane injures, especially in children with eardrum retractions.

The main benefit of endoscope-assisted $\mathrm{CI}$ is the improved visibility of the RW region. The addition of transfacial recess endoscopic examination into the conventional approach is a helpful technique, which may reduce the risk of complications by eliminating surgical exposure and orientation problems, especially in patients with difficult anatomy such as cochlear morphological abnormalities or congenital malformations. The difficulty in the surgical exposure of the RW cannot be reliably predicted by the subjective evaluation of the preoperative CT scans and more studies are needed to obtain reliable criteria.

\section{CONFLICT OF INTEREST}

No potential conflict of interest relevant to this article was reported.

\section{REFERENCES}

1. House WF. Cochlear implants. Ann Otol Rhinol Laryngol. 1976 May-Jun;85 suppl 27(3Pt2):1-93.

2. Terry B, Kelt RE, Jeyakumar A. Delayed complications after cochlear implantation. JAMA Otolaryngol Head Neck Surg. 2015 Nov;141 (11):1012-7.

3. Olgun Y, Bayrak AF, Catli T, Ceylan ME, Aydin R, Duzenli U, et al. Pediatric cochlear implant revision surgery and reimplantation: an analysis of 957 cases. Int J Pediatr Otorhinolaryngol. 2014 Oct;78 (10):1642-7.

4. Tarkan O, Tuncer U, Ozdemir S, Surmelioglu O, Cetik F, Kiroglu M, et al. Surgical and medical management for complications in 475 consecutive pediatric cochlear implantations. Int J Pediatr Otorhinolaryngol. 2013 Apr;77(4):473-9.

5. Loundon N, Blanchard M, Roger G, Denoyelle F, Garabedian EN. Medical and surgical complications in pediatric cochlear implantation. Arch Otolaryngol Head Neck Surg. 2010 Jan;136(1):12-5.

6. Bibas A, Phillips S, Bailey CM, Papsin BC. Chronic suppurative otitis media following paediatric cochlear implantation. Cochlear Implants Int. 2006 Sep;7(3):167-78. 
7. Colletti V, Fiorino FG, Carner M, Pacini L. Basal turn cochleostomy via the middle fossa route for cochlear implant insertion. Am J Otol. 1998 Nov;19(6):778-84.

8. Kronenberg J, Migirov L, Dagan T. Suprameatal approach: new surgical approach for cochlear implantation. J Laryngol Otol. 2001Apr; 115(4):283-5.

9. KiratzidisT, ArnoldW, IliadesT.Veria operation updated. I.The transcanal wall cochlear implantation. ORL J Otorhinolaryngol Relat Spec. 2002 Nov-Dec;64(6):406-12.

10. Hausler R. Cochlear implantation without mastoidectomy: the pericanal electrode insertion technique. Acta Otolaryngol. 2002 Oct; 122(7):715-9.

11. Huang CC, Lin CY,Wu JL. Retrofacial approach of cochlear implantation in inner ear malformation with aberrant facial nerve: a case report. Auris Nasus Larynx. 2006 Jun;33(2):179-82.

12. Sennaroglu L, Aydin E. Anteroposterior approach with split ear canal for cochlear implantation in severe malformations. Otol Neurotol. 2002 Jan;23(1):39-42.

13. Warren FM, Balachandran R, Fitzpatrick JM, Labadie RF. Percutaneous cochlear access using bone-mounted, customized drill guides: demonstration of concept in vitro. Otol Neurotol. 2007 Apr;28(3): 325-9.

14. Carfrae MJ, Foyt D. Intact meatal skin, canal wall down approach for difficult cochlear implantation. J Laryngol Otol. 2009 Aug;123(8): 903-6.

15. Guneri EA. Endoscopic cochlear implantation procedures. Turk Klin J Ear NoseThroat 2016 Mar;9(1):46-51.

16. Slavutsky V, Nicenboim L. Preliminary results in cochlear implant surgery without antromastoidectomy and with atraumatic electrode insertion: the endomeatal approach. Eur Arch Otorhinolaryngol. 2009 Apr;266(4):481-8.

17. Lavinsky L, Lavinsky-Wolff M, Lavinsky J.Transcanal cochleostomy in cochlear implantation: experience with 50 cases. Cochlear Implants Int. 2010 Dec;11(4):228-32.

18. Kiumehr S, Mahboubi H, Middlebrooks JC, Djalilian HR. Transcanal approach for implantation of a cochlear nerve electrode array. Laryngoscope. 2013 May;123(5):1261-5.

19. Marchioni D, Grammatica A, Alicandri-Ciufelli M, Genovese E, Presutti L. Endoscopic cochlear implant procedure. Eur Arch Otorhinolaryngol. 2014 May;271(5):959-66.

20. Dia A, Nogueira JF, O'Grady KM, Redleaf M. Report of endoscopic cochlear implantation. Otol Neurotol. 2014 Dec;35(10):1755-8.

21. Franz BK, Clark GM, Bloom DM. Surgical anatomy of the round window with special reference to cochlear implantation. J Laryngol Otol. 1987 Feb;101(2):97-102.

22. Dahm MC, Shepherd RK, Clark GM. The postnatal growth of the temporal bone and its implications for cochlear implantation in children. Acta Otolaryngol Suppl. 1993;505:1-39.

23. Leong AC, Jiang D, Agger A, Fitzgerald-O'Connor A. Evaluation of round window accessibility to cochlear implant insertion. Eur Arch Otorhinolaryngol. 2013 Mar;270(4):1237-42.

24. Kashio A, Sakamoto T, Karino S, Kakigi A, Iwasaki S, Yamasoba T. Predicting round window niche visibility via the facial recess using high-resolution computed tomography. Otol Neurotol. 2015 Jan;36 (1):e18-23.

25. Fouad YA, Elaassar AS, El-Anwar MW, Sabir E, Abdelhamid A, Ghonimy M. Role of multislice CT imaging in predicting the visibility of the round window in pediatric cochlear implantation. Otol Neurotol. 2017 Sep;38(8):1097-103.

26. Marchioni D, Soloperto D, Colleselli E, Tatti MF, Patel N, Jufas N. Round window chamber and fustis: endoscopic anatomy and surgical implications. Surg Radiol Anat. 2016 Nov;38(9):1013-9.

27. Singla A, Sahni D, Gupta AK, Loukas M, Aggarwal A. Surgical anatomy of round window and its implications for cochlear implantation. Clin Anat. 2014 Apr;27(3):331-6.

28. Meshik X, Holden TA, Chole RA, Hullar TE. Optimal cochlear implant insertion vectors. Otol Neurotol. 2010 Jan;31(1):58-63.

29. Migirov L, Shapira Y,Wolf M.The feasibility of endoscopic transcanal approach for insertion of various cochlear electrodes: a pilot study. Eur Arch Otorhinolaryngol. 2015 Jul;272(7):1637-41.

30. Hamamoto M, Murakami G, Kataura A. Topographical relationships among the facial nerve, chorda tympani nerve and round window with special reference to the approach route for cochlear implant surgery. Clin Anat. 2000;13(4):251-6.

31. Tarabichi M, Nazhat O, Kassouma J, Najmi M. Endoscopic cochlear implantation: call for caution. Laryngoscope. 2016 Mar;126(3):68992.

32. Bruijnzeel H, Ziylan F, Cattani G, Grolman W,TopsakalV. Retrospective complication rate comparison between surgical techniques in paediatric cochlear implantation. Clin Otolaryngol. 2016 Dec;41(6): 666-72.

33. Marchioni D, Alicandri-Ciufelli M, Mattioli F, Nogeira JF, Tarabichi M, Villari D, et al. From external to internal auditory canal: surgical anatomy by an exclusive endoscopic approach. Eur Arch Otorhinolaryngol. 2013 Mar;270(4):1267-75.

34. Tarabichi M, Kapadia M. Principles of endoscopic ear surgery. Curr Opin Otolaryngol Head Neck Surg. 2016 Oct;24(5):382-7.

35. Labadie RF, Balachandran R, Noble JH, Blachon GS, Mitchell JE, Reda FA, et al. Minimally invasive image-guided cochlear implantation surgery: first report of clinical implementation. Laryngoscope. 2014 Aug;124(8):1915-22.

36. Venail F, Bell B, Akkari M,WimmerW,Williamson T, Gerber N, et al. Manual electrode array insertion through a robot-assisted minimal invasive cochleostomy: feasibility and comparison of two different electrode array subtypes. Otol Neurotol. 2015 Jul;36(6):1015-22.

37. Orhan KS, Polat B, Celik M, Comoglu S, Guldiken Y. Endoscopic-assisted cochlear implantation: a case series. J Int Adv Otol. 2016 Dec; 12(3):337-40. 